\title{
A cruz e a família contra a foice e o martelo. 0 anticomunismo no movimento operário de São Paulo (1950-1964)
}

Murilo Leal Pereira Neto

Mestre em História Social - USP; Professor na Universidade do Grande ABC. São Paulo - SP [Brasil] mlealpereira@terra.com.br 


\section{Introdução}

É bastante conhecida a importância do anticomunismo como um dos componentes ideológicos da campanha promovida pelo núcleo sóciopolítico, que René Armand Dreyfuss qualificou como "elite orgânica", na preparação do golpe civil-militar de 1964. Embora também estudada, pouco se sabe da articulação do meio sindical nessa campanha, por esse motivo, neste artigo procura-se analisar o anticomunismo como uma visão conservadora de mundo que prevaleceu no Sindicato dos Metalúrgicos de São Paulo, numa conjuntura muito específica: de 1950 a 1953, no curto período em que a "velha guarda" ministerialista ${ }^{1}$, formada durante o Estado Novo, começou a ser afastada pela ascensão de uma nova coalizão formada por sindicalistas janistas, socialistas e comunistas.

Ressalta-se ainda, neste estudo, o ressurgimento dos "ministerialistas" após o golpe de 64 . Em seu término, argumenta-se sobre a importância para a classe dominante da adesão do operariado a uma representação conservadora da sociedade.

O governo militar interveio em $70 \%$ dos sindicatos com cinco mil ou mais filiados (DREYFUSS, 1987), mas quem eram os interventores, ou os diretores que receberam os sindicatos das mãos dos interventores após um breve período? No Sindicato dos Têxteis e dos Químicos, tratava-se de homens da velha guarda "ministerialista", formada no Estado Novo; no dos metalúrgicos, eram representantes de uma nova geração que, entretanto, articulava apoio daquela corrente (FONTES, 1997, p. 144). Esses vínculos sugerem a necessidade de se pensar o anticomunismo no meio sindical, numa duração maior do que a conjuntura de preparação do golpe de 1964. A campanha desencadeada pelo "complexo IPES-IBAD” (Instituto de Pesquisas e Estudos
Sociais-Instituto Brasileiro de Ação Democrática) reacendeu e articulou um conjunto de elementos que compunham uma "visão de mundo" conservadora, que vinha sendo construída pelo Estado, pela Igreja e por entidades empresariais, desde os primeiros anos da "Era Vargas". Tanto lá quanto depois, na preparação do golpe de 1964, o anticomunismo dirigia-se, como argumenta Damião Duque de Farias, “[...] à sociedade civil inteira, e principalmente às classes populares e suas organizações [...]" (1998, p. 84), expressando uma forma de reconhecimento da presença do operariado no cenário político e social brasileiro.

Francisco Foot Hardman (2002) nos lembra que foi, provavelmente, nos idos do século XIX, ecoando as repercussões da Comuna de Paris de 1871, que as classes dominantes levantaram pela primeira vez a bandeira do anticomunismo no Brasil. Mais tarde, o emprego do vocábulo "comunista" como sinônimo de incendiário ou terrorista encontraria, no contexto da Revolução Russa e durante a "Guerra Fria”, amplo terreno para expandir-se no discurso das classes dominantes. A chamada "Guerra Fria", com a Revolução Cubana, voltou a ser um fator a influenciar fortemente a política interna dos países latino-americanos, especificamente a partir de 1961. Cabe observar, porém, que a nova ofensiva conservadora dos anos 1960 encontrou um terreno preparado pela visão de mundo decorrente da articulação Estado-Igreja-empresários e que, desde os anos 1930, vinha influenciando diversas classes e setores sociais. Vejamos como essa visão de mundo se apresentava no sindicalismo dos metalúrgicos que lhe dava suporte.

Em janeiro de 1951, ocorreram eleições do Sindicato dos Trabalhadores nas Indústrias Metalúrgicas, Mecânicas e de Material Elétrico de São Paulo (doravante denominado Sindicato dos 
Metalúrgicos), tendo sido vitoriosa a chapa encabeçada por Joaquim Ferreira - que fora diretor na década de 1940 e, em 1951, tesoureiro da Federação dos Metalúrgicos -, resultado de "[...] uma frente entre os ministerialistas e a oposição, onde se achavam os esquerdistas" (PAES, 1979, p. 177). A cabeça da chapa derrotada era integrada por Mário Sobral, presidente do Sindicato, representante da velha guarda ministerialista.

Por meio da análise das edições do jornal do sindicato, O Metalúrgico, de 1950, é possível recompor os parâmetros da visão de mundo conservadora defendida pela corrente "ministerialista”. A nosso ver essa visão compunha-se das seguintes representações:

a) Anticomunismo difuso, associado à idéia de extremismo, subversão e ameaça de desagregação da organização sindical e da própria ordem social. Epíteto impingido contra a oposição sindical;

b) Representação hierárquica e "deferente" da sociedade e da relação entre operários e autoridades;

c) Defesa da família, do matrimônio e do papel feminino no lar como fundamentos da boa ordem social;

d) Representação negativa do operário como causador de seus próprios males, em razão do analfabetismo, da imperícia no trabalho, que produzia "infortúnios", e do descuido com sua saúde e corpo;

e) Defesa de um projeto de futuro: a "revolução branca".

Examinemos cada um desses aspectos. Com relação ao anticomunismo, cabe lembrar que o Partido Comunista do Brasil (que passou a denomi- nar-se PCB a partir de 1960) possuía forte presença no movimento operário metalúrgico, tendo organizado greves fora do sindicato desde 1946, liderado a construção de comissões de fábricas em várias indústrias e promovido tentativas de organização de associações sindicais paralelas à estrutura oficial.

O discurso anticomunista durante a gestão de Mário Sobral, em 1950, tinha um alvo preciso: desqualificar a oposição sindical em geral. Cabe notar, porém, que raramente ele era verbalizado em termos políticos, preferindo-se um enunciado difuso, emocional, falando-se de genérica ameaça à boa ordem. Um dos poucos artigos em que o comunismo era mencionado abertamente veiculava entrevista com o Ministro do Trabalho Danton Coelho, e foi publicado em O Metalúrgico, de junho de 1950. A entrevista trata da exigência do atestado de ideologia nas eleições sindicais que ocorreriam no dia 22 de dezembro: "Aludindo ao atestado de ideologia política [o ministro] disse que também se trata de exigência legal e não do Ministério", lembrando que, nos Estados Unidos, havia a Lei Taft, que também exigia "[...] a declaração de não ser comunista, não fazer parte de partido comunista e não estar filiado a qualquer corrente política ou ideológica que tenha por finalidade destruir o Estado democrático" (O METALÚRGICO, jun. 1950, p. 12). Cabe lembrar que a Lei Taft-Hartley fora aprovada em junho de 1947, como parte de um movimento mais amplo de "caça às bruxas", desencadeado pela administração Truman, que "[...] reduzia de maneira radical o exercício dos direitos sindicais e exigia de todo responsável sindical a assinatura de uma declaração juramentada afirmando não pertencer nem haver jamais pertencido ao PC." (DEBOUZY, 1986, p. 105).

Também podia ser considerada atitude "extremista e subversiva" fazer pichações contra 
o imposto sindical. Em um artigo de março de 1950, Pedro Gilardi Filho condenou indivíduos que perdiam dias de trabalho "[...] para rabiscar nos muros das fábricas dizeres ou frases mencionando ser inconstitucional o desconto do respectivo Imposto Sindical". O articulista argumentava que, “[...] não ligando a esses meios de propaganda extremista e subversiva [...]"(GILARDI FILHO, 1950, p. 1), o sindicato aplicava o imposto em benefício da categoria “" [...] e não como erradamente dizem as frases dos propagandistas extremistas, isto é, que o dinheiro é para sustentar pelegos e traidores da classe."(GILARDI FILHO, 1950, p. 1).

Em outros momentos, o discurso da intolerância podia assumir uma feição mais violenta. $\mathrm{Na}$ coluna "Martelando", em abril de 1950, clamouse pela expulsão da oposição das assembléias. Seria necessário partir para o ataque: "É chegado o momento de impedir que a sólida estrutura do verdadeiro sindicalismo seja maculada com a baba nojenta desses êmulos destruidores... Avante, pois!... Fora com eles!..." (O METALÚRGICO, abr., 1950, p. 18).

Duque de Farias argumenta que o anticomunismo, na propaganda católica dos anos 1930, aparecia ligado a representações de ateísmo, opressão, fracasso, mentira e astúcia. Era, porém, no princípio da luta de classes que residia o antagonismo fundamental entre o pensamento conservador (católico e não-católico), organicista e defensor da "[...] colaboração de classes [...]", e o pensamento socialista. (FARIAS, 1998, p. 76). Nessa visão organicista da sociedade, caberia ao operário deferência às autoridades e cordialidade para com os patrões. Assim, podemos perceber a representação "deferente" do relacionamento entre operários e patrões no artigo "Exame de Consciência", assinado por Cindia Pedraz Forgado, em dezembro de 1950:
Operário amigo, daqui ou de onde sejas, vou conversar contigo: tu, que és filho de Deus como toda a humanidade, que frues também o ar, a luz, o perpassar da brisa [...] porque insistes em ser um revoltado mantendo baixa a fronte, trazendo em riste a lança da agressividade? [...] Crê que teu superior é um ser igual a ti, apenas mais capaz; e talvez te precedendo no posto que irá ter! [...] Não mais o cumprimentes com a expressão cerrada lançando-lhe um "bom dia" que soe como pedrada! Nem digo que desfaças-te em mesuras rebaixantes; põe sim, em tua voz cordial fraternidade, respeitosa por certo; que ordem exprime paz; ele há de bem prezar-te, pois estarás provando exata compreensão de teu valor moral! (FORGADO, 1950, p. 9).

O terceiro aspecto da visão de mundo conservadora no meio operário é fornecido pela representação da família, da mulher e do casamento. Cabe assinalar que são freqüentes os artigos sobre o tema, de 1950 a 1952, nos quais a constituição da família e a reprodução da espécie são exaltados como atributos positivos do matrimônio:

O Matrimônio é o elo que une duas vidas para um objetivo básico e primordial - a continuação da espécie humana [...] É lamentável e doloroso constatar que ainda haja criaturas que consideram o matrimônio como fonte de satisfação dos seus desejos sexuais, doentios e perversos [...] Felizes aqueles que, unidos pelo matrimônio, produto de um amor sincero, constituem família e podem assistir na sua velhice a repetição dos seus atos em

Dialogia, São Paulo, v. 6, p. 33-42, 2007. 
seus filhos, porque eles cumpriram com seus deveres para com a Natureza que nos ensina: viver, amar e ter filhos. (TAROK, 1950, p. 2).

É interessante observar que no período seguinte, quando vai emergindo e se construindo uma "visão de mundo proletária" (que iremos especificar mais adiante), essa representação da família, como esteio da ordem, como valor supremo, é mantida, mas sofre "distorção de significado", sendo então apresentada como argumento em prol da luta por reajustes salariais, por direitos como o abono de natal (13 salário) ou o salário-família, sendo apontados os 'tubarões' ou as autoridades insensíveis como responsáveis pela desagregação familiar.

o quarto aspecto da visão de mundo conservadora consiste na representação negativa do operário, que seria responsável por seus próprios males. $\mathrm{O}$ analfabetismo, a ignorância, a imperícia no trabalho e o descuido com a saúde, destacando-se neste aspecto o alcoolismo, são apresentados como práticas a serem combatidas e, ao mesmo tempo, como justificativas para a necessidade de uma tutela por parte das autoridades, tema, aliás, bem estudado por Maria Auxiliadora Guzzo Decca que tratou sobre a atuação das agências do Estado entre os anos 1920 e 1934 (DECCA, 1987).

No artigo "A educação e o lar", de Aurora Saraiva, publicado em $O$ Metalúrgico de fevereiro de 1950, afirmava-se que "[...] o analfabetismo é, sem contestação, o pior mal do Brasil." Segundo a autora "[...] a falta de cultura motiva o descalabro, a ruína e a desgraça de nossa gente." Defeitos morais e mesmo físicos são apresentados como “[...] o resultado de uma educação insuficiente, de uma vida fundamentada na ignorância que faz de grande parte de nossa gente pessoas incapazes de raciocinar. Limitam-se a imitar e obedecer." A cultura popular era desqualificada, fosse a música ou os saberes médicos informais. Eram criticados os "sambas achincalhantes que enaltecem a vadiagem e a perversidade" e as receitas médicas das comadres de bairro. Era mencionado o caso de uma mãe que pretendeu estancar, com teia de aranha, o sangue do corte no pé de uma criança, causado por caco de vidro. "Esta 'receita' lhe foi dada por uma comadre, dessas 'sabichonas' que com uma reza só benzem e curam: quebranto, 'bichas' etc.” Ao invés de fiar-se em "curandeiras", a dona de casa deveria freqüentar cursos especializados de puericultura, adquirindo noções básicas sobre higiene, alimentação, nutrição: “[...] Seria o ideal para se evitar a calamidade que se vai ampliando assustadoramente [...]" (SARAIVA, 1950, p. 4).

De maneira menos explícita, o jornal do Sindicato também sugere que o próprio operário poderia ser responsável por seus "infortúnios" no trabalho, como a doença profissional adquirida pelo trabalhador que executa tarefas insalubres, e que os acidentes teriam múltiplas causas. Na Inglaterra, durante a Segunda Guerra Mundial, por exemplo, registraram-se diversos fatores provocadores de acidentes, tais como aumento da mão-de-obra feminina em indústrias perigosas; fadiga; serviços pesados exigidos a certos trabalhadores; admissão de trabalhadores em idade avançada; falta de técnicos e de orientadores, além do aumento das enfermidades. Nesse contexto, os trabalhadores não poderiam descuidar-se: "Os infortúnios do trabalho - quer a doença, quer o acidente - têm, destarte, no próprio homem um dos seus principais fatores, os quais, ligados diretamente à natureza do trabalho, dão anualmente um forte 'déficit' à economia do país”. (O METALÚRGICO, fev.1950, p. 5). 
No entanto, não era apenas no trabalho que o próprio homem poderia ser fator de seu infortúnio. A "vida fora das fábricas", vivida sem regra nem saber, podia também trazer conseqüências nefastas para a saúde física e mental do trabalhador e de sua família, justificando, por isso, a intervenção das autoridades ou das agências competentes, apresentando-se, entre elas, o sindicato. É o que revela a pequena coluna "Preceitos do Dia", mantida em $O$ Metalúrgico pelo menos desde o início da série que pesquisamos, de janeiro de 1950 até agosto de 1952, quando aparece pela última vez. A coluna interpelava, de forma maternal, o operário e a operária, aconselhando-os em casos de doenças, educação dos filhos, alcoolismo etc. Na coluna publicada em junho de 1950, recomendava-se respirar pelo nariz, e não pela boca, pois assim "[...] o ar chega aos pulmões isento de impurezas [...]", e não demonstrar cuidados exagerados com os filhos doentes: "Evite que seu filho se torne tímido e indeciso, mostrando-lhe ânimo e firmeza diante dos lances desfavoráveis." (O METALÚRGICO, jun. 1950, p. 5). Em outro momento, o leitor era lembrado de que secreções poderiam estar em objetos, corrimões, puxadores: "Livre-se do germe da gripe lavando as mãos freqüentemente, com água e sabão." (O METALÚRGICO, jul./ago. 1950, p. 6). Também o lazer deveria ser programado: "O repouso depois das horas de trabalho é indispensável. Mas não é descanso que precisam os que se dedicam às ocupações sedentárias e monótonas, em vez de repouso, devem procurar recreações que exijam movimento e atividade." (O METALÚRGICO, nov. 1950, p. 7). As bebidas alcoólicas, obviamente, deveriam ser evitadas: "As bebidas alcoólicas não mitigam a sede e intoxicam o organismo, enfraquecendo as defesas naturais contra as infecções, defesas essas que nenhum medicamento pode substituir. Para matar a sede, use água, leite, sucos de fruta (tamarindo, laranja, abacaxi, etc.)" (O METALÚRGICO, abr. 1951, p. 2).

O quinto e último aspecto que pudemos identificar da visão de mundo conservadora refere-se ao "projeto de futuro" proposto para a sociedade. O artigo "Façamos a Revolução Branca", de Antônio Borges, publicado em março de 1950, é bem representativo desse tópico. Impressiona por seu tom antecipatório do que mais tarde se constituiria como o projeto de modernização conservadora da ditadura militar. Modernizador quanto ao desenvolvimento econômico e à renovação tecnológica, conservador quanto às relações sociais. Escreve o articulista: "Em nenhum tempo da nossa história da humanidade [sic] a luta pelo progresso se processou com tanta vertiginosidade como na segunda metade do século que atravessamos." Entretanto, o lado moral não teria evoluído da mesma forma; em razão disso, haveria muitos órfãos de pai ou mãe necessitando de creches e escolas e muitos 'órfãos' com pai e mãe. Dessa situação nasceria "[...] a enfermidade moral e putrefata da sociedade do tempo que estamos vivendo". A solução não estaria nos "homens providenciais" nem nos "ismos", mas "em nós mesmos". Para enfrentar o problema deveria recorrer-se aos sindicatos, associações de classe, Serviço Social da Indústria (SESI), Serviço Social do Comércio (SESC), meios religiosos, tais como Associação Cívica Feminina, Liga das Senhoras Católicas, Mocidade Espírita, Departamento de Menores da Fraternidade Rosa Cruz. Todos deveriam juntar-se para fazer uma "Revolução Branca":

Na proporção em que o progresso material e científico avança em todas as partes do mundo, constitui um dever indeclinável, darmos todo nosso apoio a esta força, não

Dialogia, São Paulo, v. 6, p. 33-42, 2007. 
só contribuindo com nossa ajuda moral, mas também material, e se dermos o necessário apoio a esta plêiade de pessoas e sentimentos nobres, cujo grau de elevação, falam por si mesmos, estaremos FAZENDO A REVOLUÇÃO BRANCA, antes que o povo a faça. A revolução feita pelo povo trará "sangue, suor e lágrimas", e esta, feita por esta pequena, mas poderosa força do bem, trará sorrisos, festas e homenagens. (BORGES, mar.1950, p. 5, grifo do autor).

O timbre particularmente moralista do discurso dos "ministerialistas" no Sindicato dos Metalúrgicos foi impresso, provavelmente, por influência da atividade dos Círculos Operários Católicos. Na documentação consultada, são mencionados em dois momentos: em setembro de 1951, foi publicada uma nota de congratulação com a Federação dos Círculos Operários de São Paulo por oferecer um curso de formação sindical de dois anos, com as disciplinas de oratória, português, geografia, sindicalismo, leis trabalhistas, previdência e seguro social (O METALÚRGICO, set. 1951, p. 7). Em dezembro, era registrada a inauguração desse curso, em nota assinada por Pedro Gilardi Filho, já conhecido nosso pela redação do artigo sobre o imposto sindical. A solenidade de abertura contou com a presença do Prefeito Armando de Arruda Pereira e do Padre Leopoldo Brentano, fundador dos Círculos Operários no Brasil. O significado estratégico desses cursos pode ser avaliado pelo fato de que Joaquim dos Santos Andrade 2 , presidente do Sindicato dos Metalúrgicos de São Paulo ao longo da ditadura militar, foi formado nos cursos ministrados pela Federação, além de ser indicado por ela para assumir, posteriormente, a direção do sindicato (FARIAS, 1998, p. 217).
Essa representação conservadora da sociedade, assim como os setores da burocracia "ministerialista" que a sustentavam, perdeu força e foi derrotada com a ascensão da frente que reuniu socialistas, comunistas e janistas integrados na chapa de Remo Forli, que viria a vencer as eleições de 1953, sendo reeleito, várias vezes, até 1963. Os representantes mais rematados do "ministerialismo", Mário Sobral, presidente na gestão 1950-1951; Joaquim Ferreira, presidente na gestão 1951/1953 e José Sanches Duran, presidente da Federação dos Metalúrgicos, foram expulsos do sindicato em assembléia realizada em 5 de outubro de 1952 (LIVRO DE ATAS n. 6, p. 28), e outros como Salvador Gilardi, Virgínio Baseggio e Cezar Galducci, acusados de desfalque aos cofres do sindicato, foram suspensos por tempo indeterminado. Com a ascensão da frente socialistas/comunistas/populistas, surgem novas práticas e idéias, articulando-se o que poderia ser qualificado como "representação proletária da sociedade", lembrando que não se trata de um modelo "puro". Em brevíssimas pinceladas, arriscamo-nos a dizer que se caracterizava por:

a) Maior delimitação das contradições entre "nós" e "eles", ou seja, do conflito entre interesses de operários e povo e o dos patrões e das autoridades;

b) Uma tendência maior a empregar métodos de luta de classes: greves, piquetes, passeatas, embora as petições, memoriais e participação em cargos no aparelho do Estado se mantivessem;

c) Busca de maior autonomia e independência de organização sindical: impedindo-se o exercício da tutela do Ministério do Trabalho, embora sem romper com a estrutura sindical 
e fortalecendo-se organizações por local de trabalho;

d) Um espírito mais reivindicativo: por reajuste de salários, abono de natal, salário-família, fiscalização das condições de trabalho, congelamento de preços, aplicação das leis que beneficiavam os trabalhadores, funcionamento adequado dos órgãos públicos como Justiça do Trabalho, Instituto de Previdência e Delegacia Regional do Trabalho;

e) Uma tendência maior a procurar a solidariedade de classe com a organização de intersindicais e a organização de lutas comuns.

Essa representação da sociedade, inferida a partir da leitura do jornal $O$ Metalúrgico e das Atas de Assembléia Geral e de Reunião de Diretoria, prevaleceu no Sindicato dos Metalúrgicos, de março 1953 a abril de 1964. No dia 10 de abril daquele ano, o sindicato foi avassalado pelos agentes do Departamento de Ordem Política e Social (DOPS) que, em seu relatório pericial, afirmaram: “[...] A Diretoria do Sindicato fazia agitação, dentro da dialética imposta pelo Partido Comunista, isto é, destruir o Estado, criar a desarmonia e fazer agitação." No dia 10, tomou posse a Junta Interventora, da qual faziam parte alguns metalúrgicos. Em entrevista à imprensa, seu presidente, Carlos Ferreira dos Santos, acusa os sindicalistas que estavam no comando do sindicato por quase dez anos de "profissionais do comunismo internacional".

Em agosto de 1965, ocorreram eleições e venceu a chapa encabeçada por Joaquim dos Santos Andrade, que fora membro da comissão de salários de 1961, secretário de várias assembléias gerais, de 1961 em diante e integrante da Chapa 2, derrotada nas eleições de agosto de 1963 . Na chapa de
"Joaquinzão", encontramos alguns veteranos do sindicalismo metalúrgico do período 1953-1964. Vejamos os principais nomes:

- Otávio Siqueira, no cargo de vice-presidente. Secretariou várias assembléias gerais desde 1955, foi eleito candidato a vogal de uma Junta de Conciliação de Julgamento, em assembléia metalúrgica de 1956, e novamente, em 1959, foi membro da comissão de salários de 1961;

- Orlando Malvezi, no cargo de Secretário Geral. Secretariou assembléias gerais desde 1957. Eleito na chapa encabeçada pelo comunista Afonso Delelis, em 1963, tornou-se representante do Sindicato no Conselho da Federação dos Metalúrgicos;

- Hermeto Mendes Dantas, no cargo de $1^{\circ}$ Tesoureiro, foi eleito para a comissão de salários, em 1955, assumiu o cargo de segundo tesoureiro do sindicato na chapa de Remo Forli e José de Araújo Plácido, na gestão 59/60; fez parte da diretoria na chapa Remo-Forli/ José de Araújo Plácido (1957/58); encabeçou chapa de oposição a Remo Forli nas eleições de agosto de 1961, tendo obtido 6.633 votos (enquanto a chapa de Forli recebeu 8.394), num universo de 15.219 votantes (Ata de Apuração, 25 de agosto de 1961, p. 230). Comandou a Chapa 2, de oposição contra a frente comunistas/socialistas, em 1963, tendo sido derrotado com 7.190 votos;

- Fortunato Martinelli, como membro do Conselho Fiscal, fora da comissão de salários de 1956 e presidente do Sindicato, em 55/56.

Cabe dizer que, no Sindicato dos Metalúrgicos, o golpe de 1964 não devolveu o poder aos ministe- 
rialistas, mas atraiu para um projeto anticomunista e conservador renovado um setor representativo de dirigentes sindicais que, desde 1951, havia participado da vida do sindicato, em muitos momentos, integrados à frente com os comunistas e socialistas. Portanto, o golpe de Estado eliminou a esquerda e, de cima para baixo, reencontrou e renovou o projeto conservador (da "Revolução Branca"), que, talvez possamos dizer, permanecera latente, disperso ou recuado durante nos anos 53-64 do século passado.

\section{Considerações finais}

O discurso anticomunista, moralista e religioso, propagado pelo movimento civil-militar em preparação ao golpe de 1964, "reacendeu as brasas" de uma representação conservadora da sociedade que havia deixado suas marcas no movimento metalúrgico. Uma pesquisa mais aprofundada sobre os vínculos e a trajetória social e política dos membros da diretoria encabeçada por Joaquim dos Santos Andrade poderia esclarecer-nos melhor sobre as bases de apoio da visão de mundo conservadora. No entanto, alguns aspectos podem ser antecipados: dois pontos de apoio mais visíveis eram a burocracia forjada nos moldes do Estado Novo e a Igreja, por meio de sua atividade "circulista". Neste artigo ficou claro o potencial de agências do Estado e da Igreja, ou outras, de forjar apoio a uma visão de mundo conservadora em alguns setores do movimento operário. Qualquer visão determinista sobre o avanço da consciência de classe do operariado deve ser, portanto, recusada. As razões que levaram o movimento operário a ficar paralisado diante do golpe de 1964 devem ser buscadas, entre outros fatores, também no relativo apoio obtido ou pelo menos nas dúvidas suscitadas pela propaganda conservadora, católica e anticomunista veiculada pela elite orgânica que, como vimos, deve ter ecoado num meio social já "trabalhado" por essa visão de mundo, o que deve ter contribuído para debilitar a autoridade dos dirigentes comunistas e socialistas.

\section{The cross and the family against the sickle and the hammer. The anticommunism in the workforce movement of São Paulo city (1950-1964)}

The present text analyses the constitution of a conservative representation of society between the metallurgy workforce of São Paulo city from 1950 to 1953 and its turnabout of the 1964 civil military action. It presents the various aspects which are part of this representation as well as the elements to understand the importance of the workforce sectors' support to the 1964 civil military action.

Key words: Anticommunism. Civil military action. Metallurgists. 1964. Trade union.

\section{Notas}

1 "Ministerialista" era a denominação dada, no período em questão, aos dirigentes sindicais que haviam, em sua maioria, desenvolvido carreira sindical à sombra do Ministério do Trabalho, tendo sido, em grande parte dos casos, nomeados pelo Ministro no período do Estado Novo. Mantinham posições favoráveis aos interesses do governo e do patronato. Mais tarde essa denominação cairia em desuso, prevalecendo a de "pelegos" para os dirigentes submissos ao governo e ao patronato.

2 Mais tarde, passou a ser chamado, com sentido pejorativo, de "Joaquinzão". Tornou-se símbolo do peleguismo no país. Era retificador-ferramenteiro das Indústrias Arno S. A., em São Paulo, quando se deu o golpe civil militar, de 31 de março de 1964 , ao qual Joaquim prestou apoio público, tendo, 
inclusive, participado da célebre Marcha da Família com Deus pela Liberdade. Foi nomeado interventor no Sindicato dos Metalúrgicos de Guarulhos e, em 1965, eleito presidente do Sindicado dos Metalúrgicos de São Paulo, cargo em que permaneceria até 1986, portanto, durante praticamente todo o período da ditadura militar (ABREU et al., 2001, p. 2841).

\section{Referências}

ABREU et. al. (Coord.) Dicionário histórico-biográfico brasileiro - Pós-1930. 2. ed. rev. e atual. Rio de Janeiro: Editora FGC; CPDOC, 2001.

BORGES, A. Façamos a revolução branca. $O$

Metalúrgico, São Paulo, n. 86, mar. 1950.

CAUSAS diretas de infortúnio de trabalho. $O$

Metalúrgico, São Paulo, n. 85, fev. 1950.

DEBOUZY, M. El fracaso del socialismo en Estados Unidos. In: DROZ, Jacques (Org.). História general del socialismo: de 1945 a nuestros dias. Barcelona: Ediciones Destino, 1986. p. 66-119.

DECCA, M. A. G. A vida fora das fábricas. Rio de Janeiro: Paz e Terra, 1987.

DREYFUSS, R. A. 1964: a conquista do Estado; ação política, poder e golpe de classe. 5. ed. Petrópolis: Vozes, 1987.

FARIAS, D. D. Em defesa da ordem: aspectos da práxis conservadora católica no meio operário em São Paulo (1930-1945).1. ed. São Paulo: Hucitec; História Social/ USP. 1998.
FONTES, P. Trabalhadores e cidadãos: Nitro Química - a fábrica e as lutas nos anos 50. São Paulo: Annablume/Sindicato dos Químicos e Plásticos-SP, 1997.

FORGADO, C. P. Exame de consciência. O Metalúrgico, São Paulo, n. 92, p. 9, dez. 1950.

GILARDI FILHO, P. O imposto sindical. O Metalúrgico, São Paulo, n. 86, p. 1, mar. 1950.

HARDMAN, F. F. Nem pátria nem patrão! Memória operária, cultura e literatura no Brasil. 3 ed. rev. e ampl. São Paulo: Unesp, 2002.

PAES, M. H. S. O Sindicato dos Metalúrgicos de São Paulo (1932-1951). Dissertação (Mestrado em História)- Faculdade de Filosofia, Letras e Ciências Humanas da Universidade de São Paulo, São Paulo, 1979.

PRECEITOS DO DIA. O Metalúrgico, São Paulo, n. 95, p. 2 , abr. 1951.

PROMETIDA inteira liberdade de votação nas eleições sindicais. O Metalúrgico, São Paulo, n. 88, p. 12, jun. 1950 .

SARAIVA, A. A educação e o lar. O Metalúrgico, São Paulo, n. 85, p. 4, fev. 1950.

TAROK, A. A natureza e o matrimônio. O Metalúrgico, São Paulo, n. 86, p. 2, mar. 1950.

recebido em 9 out. 2006 / aprovado em 2 jul. 2006

Para referenciar este texto:

NETO, M. L. P. A cruz e a família contra a foice e o martelo. O anticomunismo no movimento operário de São Paulo (1950-1964). Dialogia, São Paulo, v. 6, p. XX-XX, 2007.

Dialogia, São Paulo, v. 6, p. 33-42, 2007. 